\title{
Ciência Política como vocação Profissionalização de doutores em Ciência Política no Brasil, 1996-2014
}

Political Science as a vocation

Professionalization of political science PhDs in Brazil, 1996-2014

La Ciencia Política como vocación

Professionalización de doctores en ciencias politicas en Brasil, 1996-2014

(1) André Marenco ${ }^{1}$

Resumo: O problema que orienta este texto consiste em analisar se a expansão da Ciência Política no Brasil - sob a forma de instituições acadêmicas, associações científicas, produção intelectual e formação de novas gerações de pesquisadores foi acompanhada pela absorção dos novos doutores formados nessas instituições, no mercado profissional. Para isso, concentra o seu foco na observação sobre os doutores em Ciência Política e Relações Internacionais, titulados pelas instituições de pós-graduação nacionais entre 1996 e 2014. Busca-se analisar as oportunidades de profissionalização após a conclusão do doutorado, considerando emprego, renda, setores de atividade profissional e circulação geográfica entre mestrado/doutorado/ emprego.

Palavras-chave: Doutores em Ciência Política. Oportunidades de carreira. Pós-graduação. Profissionalização. Ciência Política.

Abstract: The problem that guided this text involved examining whether the expansion of political science in Brazil has been accompanied by market absorption of new $\mathrm{PhDs}$ trained in these institutions. Therefore, it focused on observing PhDs in political science who received their degrees from domestic graduate institutions between 1996 and 2014 , looking at employment, income, sectors of professional activity and geographic circulation in relation to master's degrees/doctorates/employment.

Keywords: Political science PhDs. Career oportunities. Graduate institutions. Professionalization. Political science.

Resumen: El problema que guió este texto implicó examinar si la expansión de la ciencia política en Brasil se ha visto acompañada por la absorción del mercado de nuevos

\footnotetext{
${ }^{1}$ Universidade Federal do Rio Grande do Sul (Ufrgs, Porto Alegre, RS, Brasil). autor.dados_biográficos
}

Civitas, Porto Alegre, v. 19, n. 3, p. 523-544, set.-dez. 2019

Este artigo está licenciado sob forma de uma licença Creative Commons Atribuição 4.0 Internacional, que permite uso irrestrito, distribuição e reprodução em qualquer meio, desde que a publicação original seja corretamente citada. https://creativecommons.org/licenses/by/4.0/deed.pt BR 
doctores formados en estas instituciones. Por lo tanto, se centró en la observación de doctores en ciencias políticas que recibieron sus títulos de instituciones nacionales de postgrado entre 1996 y 2014, buscando empleo, ingresos, sectores de actividad profesional y circulación geográfica en relación con maestrías/doctorados/empleo.

Palabras clave: Doctorado en ciencias políticas. Oportunidades profesionales. Instituciones de posgrado. Profesionalización. Ciencias políticas.

\section{Introdução}

A Ciência Política completou cinco décadas de desenvolvimento institucional no Brasil. Diversos trabalhos buscaram analisar vários ângulos desse processo: as origens e formação da disciplina (Miceli, 1995), agendas de pesquisa (Avritzer, Milani e Braga, 2016; Leite, Codato e Perissinotto, 2018), a influência da pós-graduação na expansão e consolidação acadêmica (Almeida, 2005; Bulcourf, Márquez e Cardozo, 2014; Marenco, 2014; 2015). Um ponto ainda cego nesse esforço de diagnóstico da construção institucional da disciplina diz respeito às oportunidades de profissionalização dos recursos humanos titulados pelos programas e centros de pesquisa em Ciência Política no Brasil. Considerando a importância que o sistema de pós-graduação nacional teve para a consolidação da disciplina no País, faz diferença saber se o investimento realizado em pesquisa científica e formação de recursos humanos produziu resultados positivos sob a forma da absorção dos doutores egressos, do local onde trabalham e seu prestígio profissional. A profissionalização dos egressos de programas e centros de pós-graduação sinaliza o potencial para as carreiras na área, incentivando essa escolha por novas gerações de investigadores, bem como capilarizando a presença de instituições responsáveis pela formação acadêmica e profissional.

O problema que orienta este texto consiste em analisar se a expansão da Ciência Política no Brasil - sob a forma de instituições acadêmicas, associações científicas, produção intelectual e formação de novas gerações de pesquisadores - foi acompanhada pela absorção dos novos doutores formados nessas instituições, no mercado profissional. Para isso, concentra o seu foco na observação sobre os doutores em Ciência Política e Relações Internacionais, titulados pelas instituições de pós-graduação nacionais entre 1996 e 2014. Busca-se analisar as oportunidades de profissionalização após a conclusão do doutorado, considerando emprego, renda, setores de atividade profissional e circulação geográfica entre mestrado/doutorado/emprego. Foram utilizados dados agregados para o conjunto da área, bem como informações discriminadas por programa de pós-graduação, buscando examinar a empregabilidade dos 
novos doutores, e se hierarquias acadêmicas, definidas pela nota obtida no processo de avaliação da Coordenação de Aperfeiçoamento de Pessoal de Nível Superior (Capes), afetam oportunidades de profissionalização. Neste trabalho foram considerados apenas doutores titulados no Brasil, não empregando informações sobre egressos de instituições estrangeiras. Em Velho (2001), Guimarães (2002), Marenco (2014), Madeira e Marenco (2016) podem ser encontradas informações sobre a formação no exterior e o seu impacto na produção científica e na formação de recursos humanos no País. Nos últimos anos, a geração de informações a partir dos bancos de dados gerados pela Coordenação Capes e pelo Centro de Gestão e Estudos Estratégicos (CGEE) do Ministério da Ciência, Tecnologia, Inovações e Comunicações (MCTI), tem oferecido registros altamente valiosos para revelar o que acontece com os mestres e os doutores após a sua titulação acadêmica. A publicação da pesquisa "Mestres e Doutores 2015: Estudos da demografia da base técnico-científica brasileira", pelo CGEE (2016) representa um marco na descoberta dessa vida após a pós-graduação, trazendo dados sobre o emprego e a renda dos egressos desse sistema.

O trabalho está estruturado da seguinte forma: inicialmente, foi revisitada a literatura sobre a profissionalização da Ciência Política; na sequência, a sua institucionalização no Brasil a partir da expansão do sistema de pós-graduação. Na terceira parte, foram analisados os dados sobre a profissionalização de doutores em $\mathrm{CP}_{\text {e }} \mathrm{RI}^{1}$, considerando idade de titulação doutoral, empregabilidade e remuneração média, bem como o tratamento desagregado por instituição universitária, considerando taxa de emprego, mobilidade territorial, setor de atividade profissional e nucleação docente. Finalmente, são apresentadas as considerações finais.

\section{Ciência Política como profissão}

A constituição da Ciência Política, como uma comunidade profissional resulta de um processo de (i) diferenciação em relação a outras disciplinas e ocupações - como direito, filosofia ou sociologia - através da fixação de uma expertise própria, conhecimentos e habilidades específicos, linguagens, conceitos, técnicas e modelos de análise, e a (ii) construção de carreiras profissionais, constituídas por sistemas de formação e recrutamento, instituições acadêmicas, demarcação de postos e salários (Easton, Graziano e Gunnel, 1991; Goodin e Klingemann, 1996; Bulcourf e Vazquez, 2004). O ponto aqui é que sem a profissionalização oferecida pela disponibilidade

\footnotetext{
${ }^{1}$ A área de Ciência Política e Relações Internacionais será referida em diante como CP e RI.
} 
de oportunidades ocupacionais próprias, não há como assegurar a fixação de uma comunidade disciplinar específica, reduzindo seus praticantes a nichos de atividades diletantes.

A profissionalização da Ciência Política adquiriu contornos mais salientes a partir do final do século 19 nos Estados Unidos com a criação de postos acadêmicos nas mais prestigiosas instituições universitárias norte-americanas. Como marcos inaugurais, deve-se destacar a fundação da School of Political Science da Columbia University, por John Burgess (1880) e, mais tarde, a criação da American Political Science Association, em 1903 e o lançamento da American Political Science Review, em 1906 (Somit e Tanenhaus, 1964; Ranney, 1965; Easton, Graziano e Gunnel, 1991; Gunnel, 2006).

Analisando a influência do sistema universitário na constituição de uma comunidade profissional de politólogos norte-americanos, Somit e Tanenhaus $(1963 ; 1964 ; 1967)$ destacaram o forte elitismo nos padrões de formação e oportunidades de recrutamento profissional promovidos por hierarquias institucionais.

Investigando o ingresso de doutores em Ciência Política em departamentos universitários entre 1902 e 2000, Grofman, Feld e Masuoka (2005) isolaram a presença de um padrão de organização vertical, caracterizado por autosseleção e potencial de colocação de egressos de instituições top ranked em outros departamentos acadêmicos. Em trabalho seguinte, os autores procuraram testar a atualidade do diagnóstico formulado por Somit e Tanenhaus (1963, 1964, 1967) revelando expansão geográfica e assimetria entre as taxas de formação mais elevadas por departamentos mais novos e ocupação acadêmica, com domínio dos departamentos melhor rankeados (Masuoka, Grofman e Feld, 2007). Empregando modelagem teórica distinta, Oprisko, Dobbs e Digrazia (2013) chegaram a conclusões semelhantes, indicando que à medida em que o prestígio departamental da alma mater declina, reduzem-se as chances de colocação profissional. Ângulos adicionais da carreira profissional de egressos de PhDs. em Ciência Política foram prescrutados em outros trabalhos: fatores de variação salarial (Claypool et al., 2017), dispersão ocupacional dos PhDs em Ciência Política (Lewis, 2017), a importância de redes de relacionamentos para oportunidades de carreiras acadêmicas (Fowler Grofman e Masuoka, 2007), acesso a carreiras fora da academia (Klarner, 2016; Gundersen, 2016; Benz, 2016; Clark, 2016).

\section{Profissionalização dos cientistas políticos no Brasil}

Em que medida, o título obtido com o doutorado na área de Ciência Política oferece oportunidades de profissionalização para os egressos do 
sistema de pós-graduação? Comparativamente, o rendimento salarial dos doutores em Ciência Política indica maior ou menor valorização no mercado de trabalho em relação às demais áreas do conhecimento? Existem diferenças na empregabilidade, padrões de mobilidade geográfica segundo nível escolar e absorção profissional quando se desagrega a informação relativa aos doutores em Ciência Política segundo cada instituição responsável pelo título doutoral? Pode-se estabelecer uma hierarquia entre as instituições de pós-graduação na área de Ciência Política e Relações Internacionais segundo potencial de nucleação e tipo de ocupação ou atividade econômica, conforme a origem institucional dos doutores titulados?

O principal objetivo deste trabalho consiste em analisar se a expansão institucional da pós-graduação em Ciência Política no Brasil foi acompanhada por uma efetiva profissionalização dos doutores titulados nessas instituições. Para identificar e mensurar a profissionalização dos doutores na área foram considerados os seguintes indicadores: (1) taxa de emprego formal dos doutores formados entre 1996 e 2014; (2) área de atividade econômica; (3) remuneração média mensal dos egressos de cursos de doutorado. Taxas elevadas de emprego formal, em áreas afins à formação profissional, acompanhados por remuneração média elevada quando comparado à outras ocupações, indicam a presença de oportunidades para carreiras profissionais aos cientistas políticos. Paralelo, foram considerados, a (4) origem institucional da titulação doutoral e, (5) mobilidade geográfica entre mestrado/doutorado/ocupação profissional, buscando observar padrões de carreiras influenciados pela hierarquia acadêmica entre as instituições responsáveis pela formação doutoral.

Os dados utilizados correspondem ao universo dos titulados no período 1996/2014 e foram obtidos com base na pesquisa "Mestres e doutores do Brasil", realizada pelo Centro de Gestão e Estudos Estratégicos (CGEE), do Ministério da Ciência, Tecnologia e Inovação (MCTI). A pesquisa do CGEE baseou-se no cruzamento de duas bases de dados: (1) as informações recolhidas anualmente pela Capes, fundação do Ministério da Educação (MEC) e empregadas na avaliação periódica da pós-graduação brasileira, especificamente aqui sobre a titulação de doutores em cada Programa de PósGraduação, e, (2) os dados contidos na Relação Anual de Informações Sociais (RAIS), do Ministério do Trabalho e Emprego, fornecidos por empregadores públicos e privados com registros individuais sobre empregados, consistindo em cadastro utilizado para a concessão de benefícios sociais pelo Governo Federal. O CGEE comparou as duas bases de dados a partir do Cadastro de Pessoas Físicas no Ministério da Fazenda (CPF) dos doutores egressos, relacionando titulados/empregados, identificando, assim, emprego, idade, 
remuneração e área de origem educacional e destino profissional. É importante salientar que os percentuais se referem a taxas de emprego formal. Ou seja, quando o cadastro de um titulado não encontra correspondência em um registro de ocupação formal, ele aparecerá como não empregado.

Os dados da pesquisa CGEE/Capes são públicos, tendo gerado pelo menos três publicações nas quais essas informações podem ser acessadas. Informações mais detalhadas sobre os procedimentos e tratamento dos dados podem ser obtidos em CGEE (2016, p. 9-19).

Evidências do potencial para a profissionalização dos doutores formados nos principais centros de pós-graduação em Ciência Política brasileiros devem ser obtidas considerando-se a empregabilidade desses titulados após a conclusão do curso. Dados de pesquisa do Centro de Gestão e Estudos Estratégicos/MCTIC, com base em dados de titulação da Capes e emprego e renda, do Ministério do Trabalho, permite avaliar a proporção de doutores formados a cada ano entre 1996 e 2014, e empregados em 31 de dezembro de 2014 (Gráfico 1).

Gráfico 1 - Taxa de emprego formal dos doutores, Ciência Política e Relações Internacionais/Capes, em 31 dez 2014, conforme ano de titulação

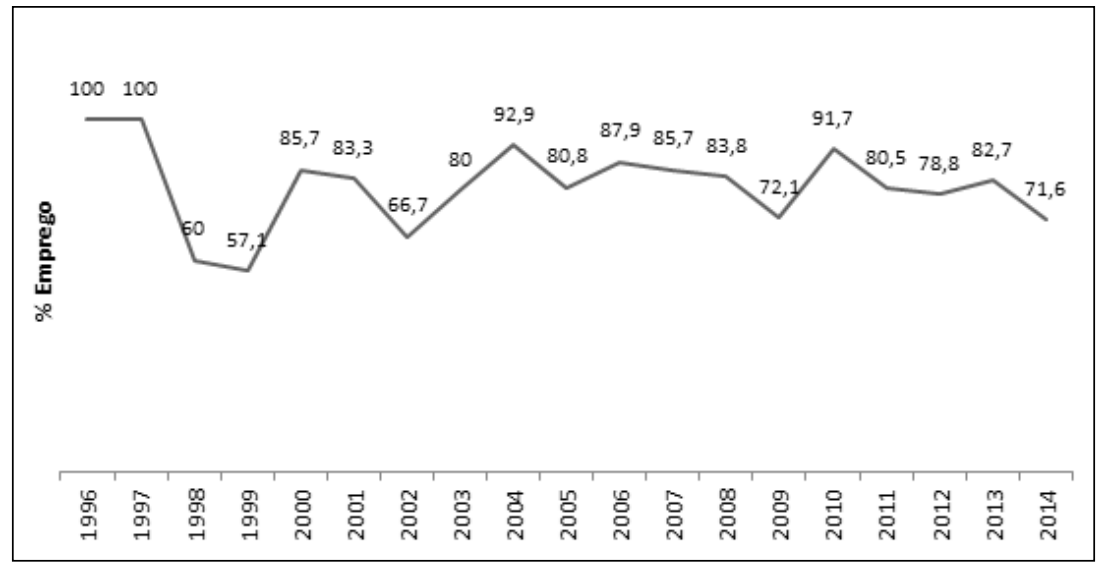

Fonte: CGEE (2016), RAIS (2014), Capes (2018).

Os dados do Gráfico 1 referem-se a doutores segundo o ano de titulação e a sua situação em 31/12/2014. Como seria de se esperar, quanto maior a distância temporal com o ano de doutoramento, maiores as taxas de emprego formal. Contudo, uma evidência da empregabilidade como indicador da profissionalização dos doutores em Ciência Política pode ser reconhecida na 
informação de que 71\% dos doutores em CP e RI formados em 2014 estavam empregados ainda no final daquele ano. Considerando a Classificação Nacional de Atividades Econômicas dos estabelecimentos empregadores (CNAE), $75,9 \%$ dos doutores em Ciência Política e Relações Internacionais estavam empregados em atividades de educação e 18,3\% na administração pública.

Em perspectiva convergente, as informações apresentadas pelo levantamento do CGEE indicam que doutores em Ciência Política e Relações Internacionais possuem a segunda mais elevada remuneração mensal média, quando comparados às áreas de avaliação/Capes, permitindo inferir forte valorização profissional (Gráfico 2).

Gráfico 2 - Remuneração mensal média de doutores titulados no Brasil há 2 anos, com emprego formal em 31/12/2014, por área de avaliação da Capes

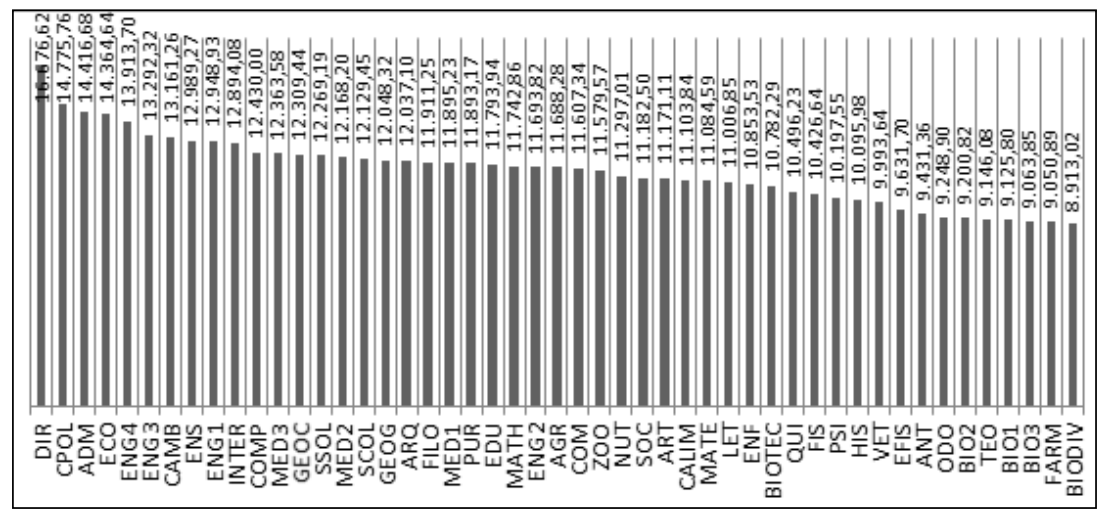

Fonte: CGEE (2016), RAIS (2014), Capes (2018).

Doutores titulados em programas de pós-graduação na área de Ciência Política e Relações Internacionais apresentaram rendimentos salariais inferiores apenas aos egressos da área do Direito, acima dos profissionais de Administração, Economia, Medicina, de áreas tecnológicas como as Engenharias e distanciados em relação a disciplinas vizinhas, como Sociologia, História ou Antropologia.

Se o potencial de profissionalização dos doutores em Ciência Política mensurada pela taxa de emprego formal de doutores - bem como os níveis de remuneração salarial são comparativamente elevados, a pergunta que cabe na sequência diz respeito a tratar-se de um padrão homogêneo ou se existem variações nas condições de profissionalização dos doutores em Ciência Política, quando considera-se a instituição responsável pela obtenção 
do título. Faz diferença para o incremento de oportunidades de emprego e renda, a antiguidade ou conceito do programa no sistema nacional de pós-graduação?

A Tabela 1 traz informações sobre o número de doutores em Ciência Política e Relações Internacionais, titulados a cada ano entre 1996 e 2014 e discriminados por programa de pós-graduação. Adicionalmente é indicado número desses doutores que estavam empregados em 31 de dezembro de 2014 e a proporção empregados/titulados.

Os valores médios relativos à taxa de emprego no período 19962014 constituíram um intervalo de distribuição entre os valores máximos apresentados pela Unicamp (95\%) e pela UFPE (94\%), e os mínimos, da UFFCP (65\%). Por outro lado, a associação entre a taxa de emprego formal e a antiguidade da instituição de pós-graduação $\left(\mathrm{R}^{2}=0,0014\right)$ ou o conceito obtido na avaliação Capes para o período 2013/16 $\left(\mathrm{R}^{2}=0,1835\right)$, revelaram que, a princípio, parece não haver relação linear entre prestígio ou institucionalização da alma mater e melhores oportunidades de obtenção de postos profissionais. Na mesma direção, duas das instituições mais antigas e com notas de excelência (UFMG e USP-CP), registraram posições apenas intermediárias no ranking de empregabilidade de seus doutores.

Nesse ponto, a dúvida diz respeito aos padrões geográficos de colocação dos doutores egressos das diferentes instituições de pós-graduação em Ciência Política. Existe um padrão de mobilidade nacional dos recém doutores da área, implicando em circulação estadual ou regional entre o curso doutoral e o emprego obtido após a diplomação? Em caso positivo, algumas instituições apresentam maior frequência de distribuição nacional de seus doutores, fora da região de origem escolar? Pode-se observar padrões nacionais versus regionais de colocação dos egressos de doutorados?

A Tabela 2 apresenta a distribuição dos doutores em Ciência Política e Relações Internacionais, formados entre 1996 e 2014, segundo as instituições de origem e a unidade da federação onde localiza-se o emprego obtido após a diplomação.

A maioria dos doutores em Ciência Política e Relações Internacionais $(60,8 \%)$ obteve vaga profissional no mesmo estado onde se titulou no doutorado. Ampliando a escala territorial para a região geográfica onde está localizada a instituição doutoral, chega-se a $73,8 \%$ de fixidez territorial. A migração profissional das regiões Sul/Sudeste, para Norte, Nordeste e CentroOeste (menos DF) correspondeu a um contingente equivalente a $14,2 \%$ dos novos doutores, enquanto a circulação entre Sul e Sudeste constituiu uma opção para apenas $5,9 \%$ dos titulados. 


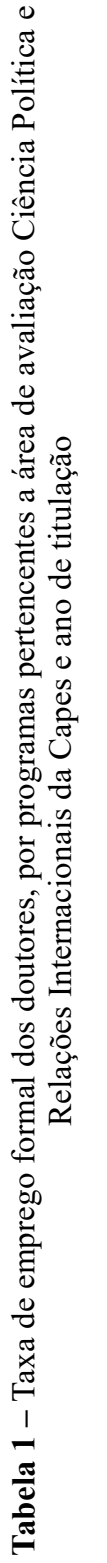

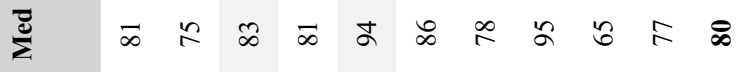

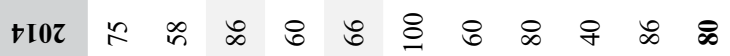

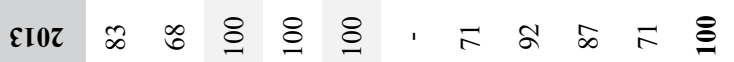

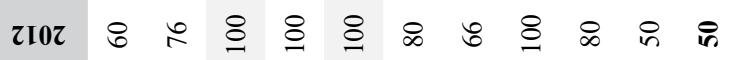

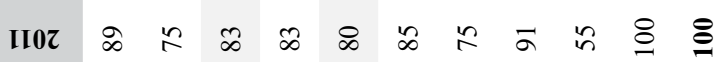
0I0t \& \& \&\&\& $\& 8 \& 1,1$

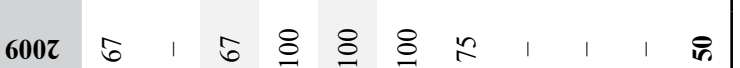

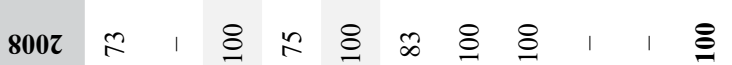

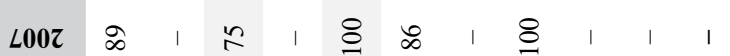

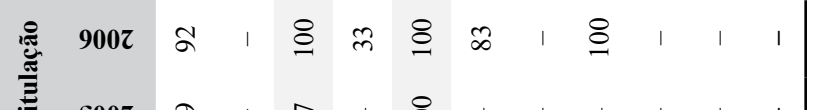

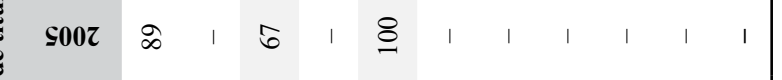
¿ E00z $\operatorname{zot} \hat{6}, \widehat{6}$ $\operatorname{I00z} \infty \infty_{\infty} \quad 1$ $0002 \approx$ $666 \mathrm{I}$ in 1 866I ̊ำ L66I $\cong$ $966 I \stackrel{8}{ }$

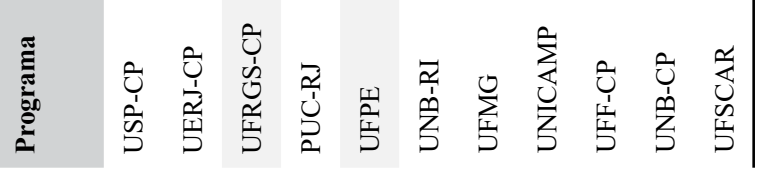

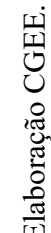

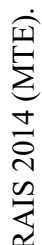
它 苍 祳 苛

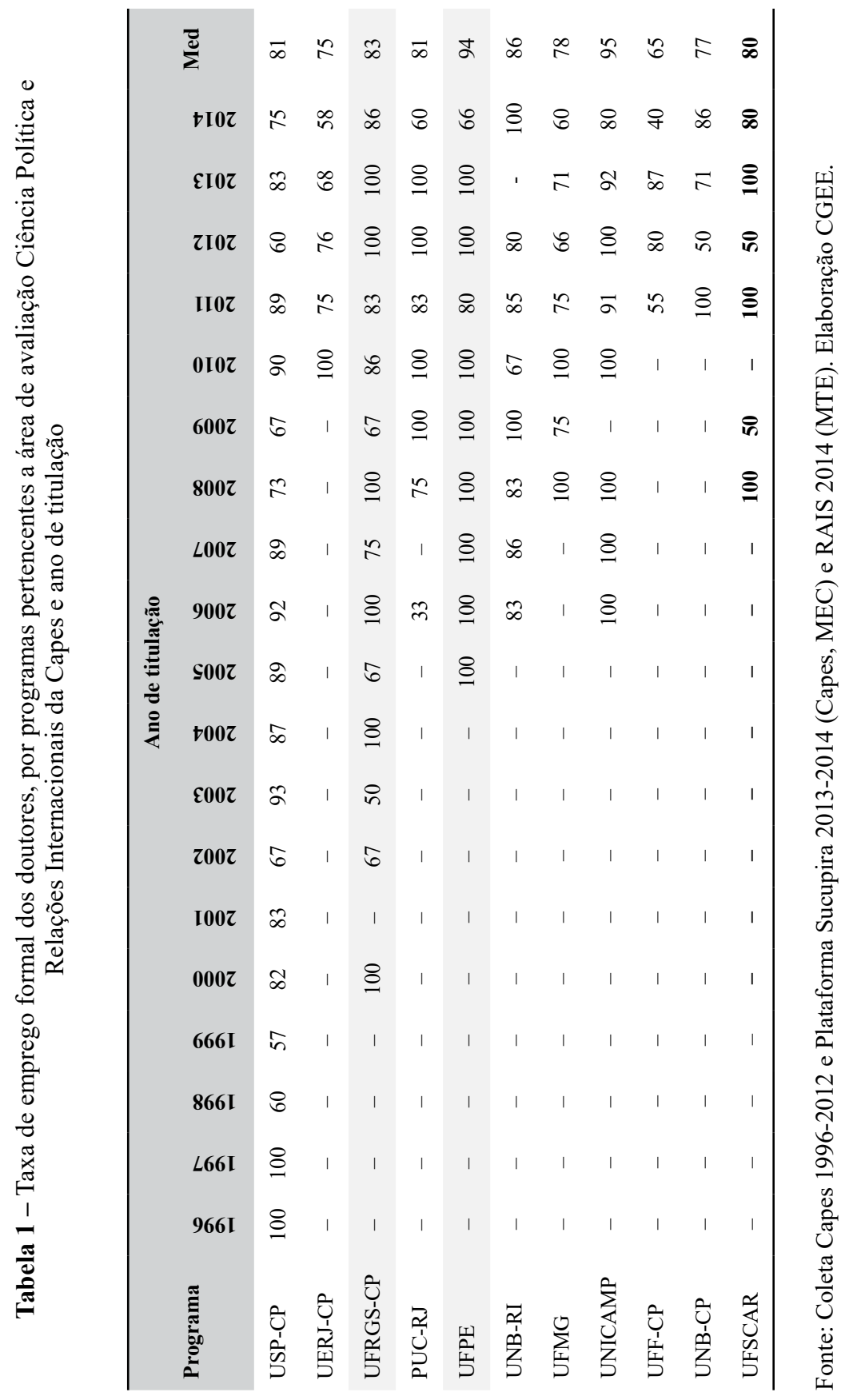




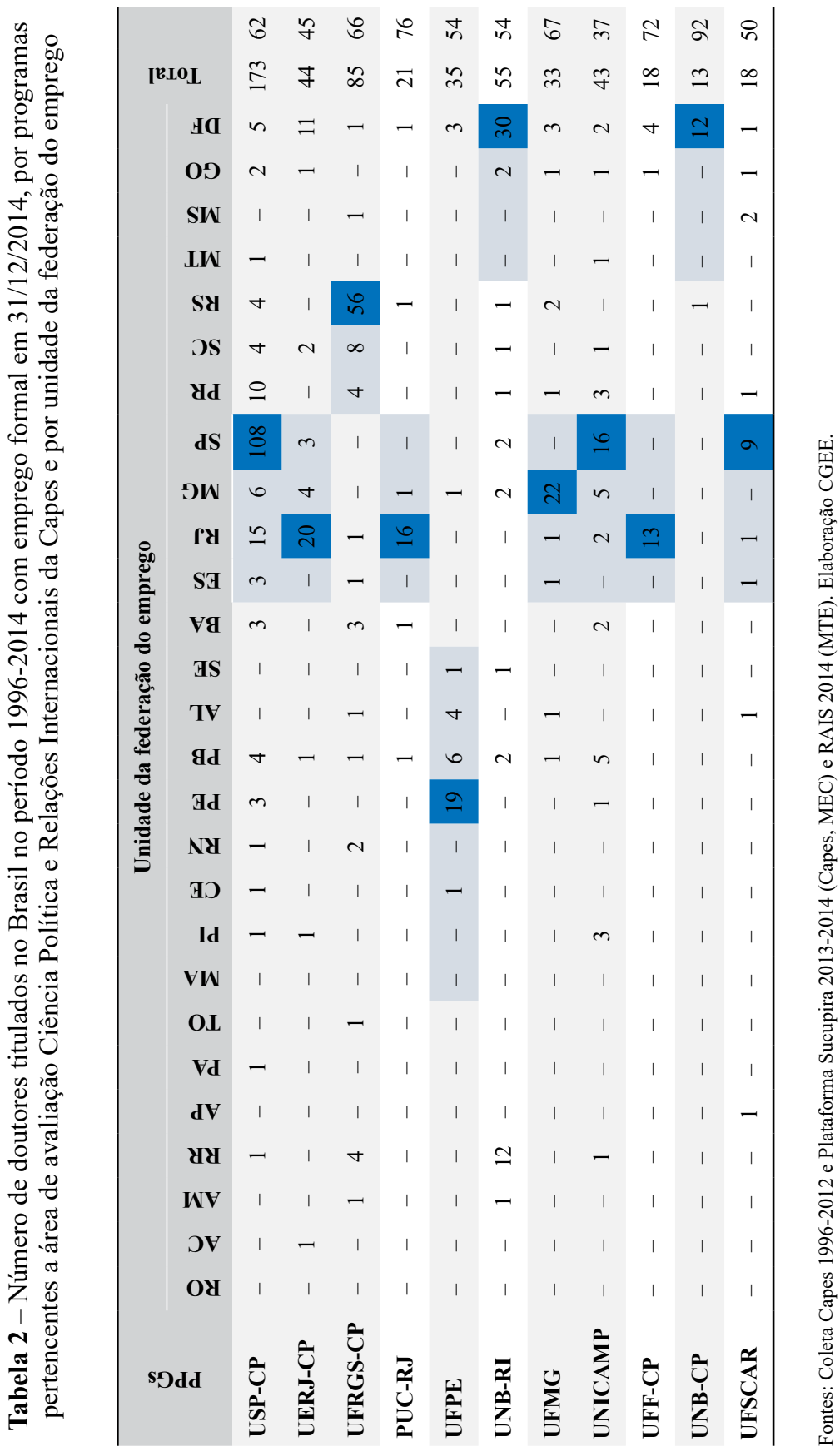


Esse comportamento se reflete também quando se desagrega a informação entre os programas de pós-graduação da área: a maioria apresenta egressos que conseguem ocupações profissionais próximo do local de sua formação doutoral. As exceções são representadas por Uerj-CP e Unicamp, onde predominam doutores empregados fora do estado da Instituição. Considerando o número de estados com doutores egressos desempenhando atividades profissionais, USP-CP (18), Ufrgs-CP (14), Unicamp (13), UnB-RI (10), apresentam as maiores dispersões territoriais, com egressos desempenhando atividades profissionais em todas as regiões geográficas do País. Finalmente, a relação entre a nota obtida por cada programa, referente ao quadriênio 2013-2016 e a nacionalização da atividade profissional dos egressos de cada instituição, apresentou índices residuais $\left(\mathrm{R}^{2}=0,0409\right)$, indicando não haver associação entre a hierarquia acadêmica e uma maior probabilidade de colocação nacional de doutores egressos. Considerando que $80,1 \%$ dos alunos de doutorado em programas de pós-graduação em Ciência Política e Relações Internacionais no período estavam cursando esse nível na mesma unidade da federação na qual haviam obtido o título de mestre, parece haver uma baixa integração nacional do sistema, traduzido em circulação interestadual e interinstitucional de aspirantes à profissionalização acadêmica. Padrões de mobilidade espacial e geográfica no Brasil, em contraste com aqueles observados nos Estados Unidos (Masuoka, Grofman e Feld, 2007), não devem ser negligenciados na consideração desse fenômeno.

As informações agregadas haviam permitido identificar uma forte concentração das ocupações profissionais dos doutores em CP e RI nas atividades de ensino e, em menor medida, administração pública. Esse padrão se mantem quando os dados são desagregados por instituição de pós-graduação?

Educação e Administração Pública constituem o destino de 9 em cada 10 doutores em Ciência Política e Relações Internacionais, diplomados em qualquer uma das instituições de doutoramento que titularam alunos entre 1996 e 2014. Atividades ligadas à produção, serviços ou finanças apresentaram frequência residual. Chama a atenção a reduzida participação em "Atividades profissionais, científicas e técnicas" e "Organismos internacionais e outras instituições extraterritoriais", essa sem nenhum registro de egresso ocupado, fenômeno paradoxal considerando a presença de cursos de doutorado em Relações Internacionais e o número de doutores titulados nessa área de concentração.

O ingresso na administração pública foi a escolha de quase dois em cada 10 doutores titulados em CP e RI no País entre 1996 e 2014. UnB-RI, UnB-CP e UFF-CP apresentaram comportamento discrepante, com parti- 
cipação majoritária de seus doutores absorvidos na administração pública. Oportunidades constituídas em decorrência de proximidade em relação à administração federal provavelmente seja um atributo favorável aos dois programas de pós-graduação do Distrito Federal; por outro lado, o caráter mais recente e o menor número de doutores formados por UnB-CP e pelo UFF-CP possam ter contribuído para gerar um viés no resultado apresentado por essas duas instituições.

Gráfico 3 - Doutores titulados por programas Ciência Política e Relações Internacionais da Capes, conforme atividades econômicas CNAE, em \%

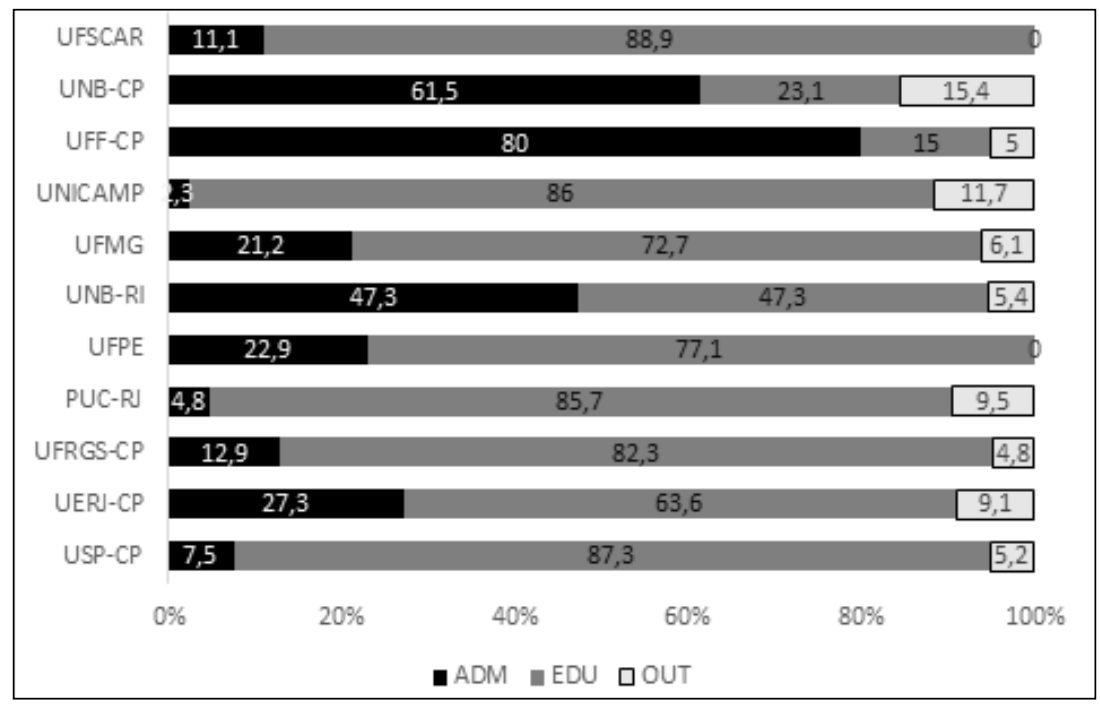

Fontes: Coleta Capes 1996-2012 e Plataforma Sucupira 2013-2014 (Capes, MEC) e RAIS 2014 (MTE). Elaboração CGEE.

Nota: (1) CNAE 2.0 (IBGE, 2007).

Educação representa a oportunidade de profissionalização de $3 / 4$ dos doutores formados pelos programas de pós-graduação da área. Em paralelo, desagregando atividades de "educação" em seus diferentes níveis (infantil, médio, superior, técnico, apoio), pode-se observar que $90 \%$ dos doutores em CP e RI formados em todos os programas de pós-graduação com doutoramento, ocupados nessa área, foram absorvidos em ocupações do "ensino superior" (CGEE, 2016). Dessa forma, aproximadamente sete em cada 10 doutores titulados por instituições na área de Ciência Política e Relações Internacionais profissionalizaram-se como professores de universidades ou 
centros universitários. Não parece possível passar despercebido a endogenia como um produto do funcionamento do sistema de pós-graduação nacional: docentes formando novos docentes. Considerando limites orçamentários para expansão ilimitada do sistema universitário, a permanência deste padrão ou a não diversificação do recrutamento profissional em outras áreas como consultorias privadas, organismos internacionais ou mesmo em administrações públicas estaduais e municipais, pode representar um gargalo futuro à profissionalização dos cientistas políticos.

Uma interrogação pertinente nesse ponto seria quanto às razões para as discrepâncias salariais reveladas no Gráfico 4, uma vez que a elevada frequência de egressos na atividade de "Educação" e a padronização federal de salários nas instituições federais de Ensino Superior deveriam equalizar a renda de doutores, a despeito de sua área de formação profissional. ${ }^{2}$ Para buscar uma explicação a esse fenômeno, considerou-se a hierarquia dos cargos na administração pública, ocupados por doutores em diferentes disciplinas da área de "humanidades". Observando a verticalização na estrutura administrativa brasileira, parece não ser a mesma coisa ocupar postos de direção ou nível superior, com responsabilidades na formulação de políticas públicas, ou estar em posições de nível médio ou, ainda, na burocracia de nível de rua. As informações da Classificação Brasileira de Ocupações (CBO) permitem uma informação mais desagregada sobre a natureza dos cargos na administração pública, visualizando com maior nitidez a localização dos doutores egressos de programas de Ciência Política no País. Cotejando as informações processadas pelo CGEE, com a classificação $\mathrm{CBO}$, pode-se identificar que a proporção equivalente a 12,9\%, do total de doutores em Ciência Política, ocupavam cargos como "membros superiores do poder público, dirigentes de organização de interesse público e de empresas" (CGEE, 2016), o que representa que cerca de $70 \%$ desses titulados que tiveram como destino profissional a administração pública, chegaram a cargos de direção ou superiores em seus órgãos. O Gráfico 4, a seguir, apresenta a relação entre a remuneração média salarial e a proporção de ocupados em "postos de direção", conforme a classificação CBO, segundo diferentes titulações doutorais da área de "humanidades".

Diferenças quanto à proporção de doutores que ocupam cargos de direção na administração pública podem explicar cerca de $80 \%$ da variação observada na remuneração média mensal de egressos com formação de doutores em diferentes disciplinas da área de humanidades. Enquanto doutores titulados nas áreas de "direito", "ciência política" e "economia" apresentam mais frequência

\footnotetext{
${ }^{2}$ Agradeço a observação arguta de um dos pareceristas anônimos quanto a este ponto.
} 
na obtenção de postos de direção na administração pública, repercutindo em mais renda média, egressos das áreas de "história", "antropologia" e "teologia" alcançam esses cargos com menos frequência, revelando, em paralelo, as menores médias de rendimento salarial nesta área.

Gráfico 4 - Relação entre proporção de ocupados em postos de direção e remuneração média, segundo diferentes áreas de humanidades

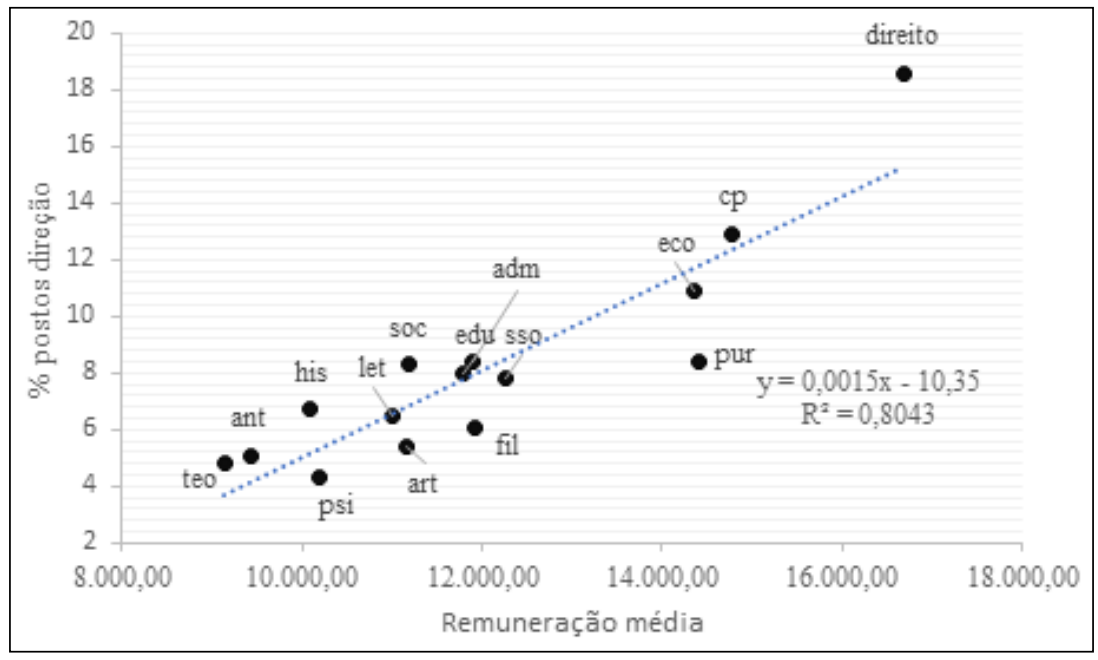

Fontes: CGEE (2016), CBO (2016).

Mais duas perguntas apresentam-se à esta altura: (i) em que medida este processo de replicação profissional configura padrão de saturação ou difusão? (ii) hierarquias acadêmicas importam na colocação profissional destas réplicas docentes? A primeira questão implica analisar se o destino universitário dos novos docentes corresponde às mesmas instituições responsáveis por seu treinamento e formação, ou localização na mesma região geográfica ou, em contraste, se a absorção no mercado de trabalho exigiu deslocamento interinstitucional e inter-regional. Em paralelo, deve-se examinar se a posição de cada instituição formadora no ranking acadêmico (conformado pelas notas no sistema de avaliação da Capes) maximiza oportunidades para inserção profissional em instituições de maior prestígio ou mais próximas geograficamente do local de formação doutoral.

Para tentar analisar esses dois problemas, a Tabela 3, extrai informações da Plataforma Sucupira, examinando os dados relativos ao corpo docente dos 43 programas de pós-graduação em funcionamento na área de Ciência 
Política e Relações Internacionais, e classificados nas clientelas "avaliação" e "acompanhamento", durante a avaliação quadrienal 2017. Foram considerados docentes "permanentes" e "colaboradores", identificando a instituição responsável por sua formação doutoral. Os PPGs - formadores e receptores - estão apresentados segundo a ordem cronológica de sua implantação A distribuição resultante está apresentada a seguir:

Tabela 3 - Instituição de doutorado dos docentes permanentes de Programas de Pós-Graduação em Ciência Política e Relações Internacionais, Avaliação Quadrienal 2017

\begin{tabular}{|c|c|c|c|c|c|c|c|c|c|c|c|c|c|c|}
\hline \multirow[b]{2}{*}{ Ppg destino } & \multicolumn{14}{|c|}{ Doutorado } \\
\hline & 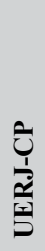 & $\tilde{\tilde{\Omega}}$ & 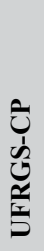 & 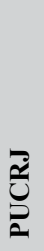 & $\frac{\sqrt[c]{2}}{\frac{1}{5}}$ & $\begin{array}{l}\bar{a} \\
\vec{b} \\
\vec{b}\end{array}$ & $\sum_{S}^{U}$ & 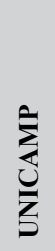 & 它 & $\begin{array}{l}\hat{U} \\
\dot{\mathbf{Z}} \\
\dot{b}\end{array}$ & 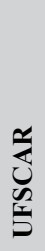 & 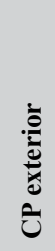 & 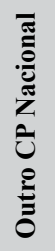 & 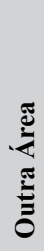 \\
\hline UFMG & 7 & 1 & & & & & 3 & & & & & 3 & & 8 \\
\hline UERJ-CP & 6 & 2 & & & & & & & & & & 8 & & 3 \\
\hline UFRGS-CP & 1 & 2 & 8 & & & 1 & & & & & & 1 & & 9 \\
\hline USP-CP & 1 & 16 & & & & & & 1 & & & & 16 & & 19 \\
\hline UNICAMP & & 6 & & & & & & 5 & & & & 1 & & 8 \\
\hline UFPE-CP & 2 & 2 & & & 7 & & & & & & & 7 & & 2 \\
\hline UNB-CP & & & & & 1 & 2 & 1 & 1 & & 1 & & 6 & & 6 \\
\hline UNB-RI & 1 & 3 & & 1 & & 3 & & & & & & 2 & & 4 \\
\hline PUC-RIO & 1 & 2 & & 3 & & & & & & & & 12 & & \\
\hline UFF-CP & 9 & 3 & & & & & & & & & & 3 & 1 & 6 \\
\hline UNESP & & 9 & & & & & & 2 & & & & 2 & 1 & 10 \\
\hline UNIEURO & & & & & & 1 & & & & & & 2 & & 9 \\
\hline PUC/MG & 2 & & & 2 & & 1 & & & & & & 2 & 2 & 5 \\
\hline UFPA & 6 & & & & & & & 1 & & & & 2 & & 4 \\
\hline FUFPI & 1 & 1 & & & & & & 5 & 1 & & & & 1 & 5 \\
\hline UEPB & & 2 & & 1 & & & & & & & & 2 & 1 & 5 \\
\hline UFF-EE & 2 & & & & & & & & 1 & & & 1 & 1 & 10 \\
\hline UFSCAR & & 5 & & & & & & 1 & & & 2 & 1 & & 6 \\
\hline UFRJ-EPI & 1 & 1 & & & & & & & & & & & 1 & 15 \\
\hline USP-RI & 1 & 8 & & & & & & & & & & 4 & & 11 \\
\hline
\end{tabular}


Tabela 3 (continuação)

\begin{tabular}{|c|c|c|c|c|c|c|c|c|c|c|c|c|c|c|}
\hline \multirow[b]{2}{*}{ Ppg destino } & \multicolumn{14}{|c|}{ Doutorado } \\
\hline & 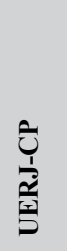 & $\hat{n}$ & $\begin{array}{l}\text { ثิ } \\
\dot{1} \\
\vdots \\
\frac{\pi}{5} \\
5\end{array}$ & $\begin{array}{l}\overrightarrow{0} \\
\underline{0} \\
\underline{0}\end{array}$ & $\frac{5}{\frac{5}{5}}$ & $\begin{array}{l}\bar{\alpha} \\
\hat{b} \\
\underline{b}\end{array}$ & $\sum_{S}^{0}$ & 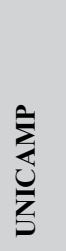 & 它 & $\begin{array}{l}\hat{U} \\
\text { Zे } \\
\text { பे }\end{array}$ & 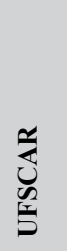 & 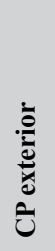 & 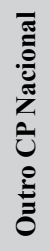 & \\
\hline UFPR & 1 & 1 & & & & & & 1 & & & 1 & & & 6 \\
\hline UERJ-RI & 4 & & & 3 & & & & & & & & 2 & & 7 \\
\hline UEM & & & & & & & & 1 & & & & & & 20 \\
\hline UFRB & & & & & & & & & & & & & & 18 \\
\hline UFSC & 2 & 1 & 1 & & & 1 & & & & & & 2 & & 9 \\
\hline UFRGS-EEI & 1 & & 4 & 1 & & & & & & & & & & 12 \\
\hline UFPEL & & & 4 & & & & 1 & & & & & & & 3 \\
\hline UNIFA & & 1 & & & & & & & & & & & 3 & 15 \\
\hline UFG & 2 & 1 & & & & 2 & 2 & 1 & 1 & & & 1 & 1 & 6 \\
\hline UEMA & & & & & & & 1 & & & & & & & 15 \\
\hline CEFOR & 7 & & & & & & & & & 1 & & & & 12 \\
\hline ECEME & 1 & 2 & & & 1 & & & & 1 & & & 3 & 1 & 13 \\
\hline UFPE-PP & & 1 & & & 6 & & & & & & & 4 & & 3 \\
\hline UFBA & & & & 1 & & & & & & & & & & 9 \\
\hline EGN & 2 & & & & & & & & 4 & & & & 1 & 8 \\
\hline UFABC & & 6 & & & & & & & & & & 1 & & 12 \\
\hline UNILA & 1 & 1 & 1 & & & & 1 & & & & & 1 & & 15 \\
\hline UFRJ-PP & & & & & & & & & & & & & 1 & 22 \\
\hline UFU & & 4 & & & & & & 5 & & & & & & 2 \\
\hline UFRGS-PP & & & 1 & & & & & & & & & & 3 & 14 \\
\hline UFPB & & 1 & 1 & & 3 & 1 & 1 & 4 & & & & & 1 & 3 \\
\hline PUC/RJ-MP & & & 4 & & & & 2 & & & 1 & & & & \\
\hline \multicolumn{15}{|l|}{ UNIPAMPA } \\
\hline TOTAL & 62 & 82 & 24 & 12 & 18 & 12 & 12 & 28 & 8 & 3 & 3 & 89 & 19 & 108 \\
\hline № Inst. destino & 23 & 25 & 8 & 7 & 5 & 8 & 8 & 12 & 5 & 3 & 2 & 25 & 14 & 42 \\
\hline $\begin{array}{l}\% \text { destino } \\
\text { mesma região }\end{array}$ & 59,7 & 80,5 & 79,2 & 66,6 & 88,9 & 66,6 & 41,7 & 50,0 & 75,0 & 66,6 & 66,6 & - & - & - \\
\hline
\end{tabular}

Fonte: Plataforma Sucupira, Capes. 
Nucleação no jargão da Capes representa a capacidade de um programa de pós-graduação para a formação de recursos humanos para outros programas de pós-graduação, aptos a ampliar a presença do sistema e de oportunidades de formação de pós-graduada (Capes, 2017). ${ }^{3}$ Considerando tanto o número de doutores absorvidos por outros programas de pós-graduação, quanto o número de instituições que contam com egressos de cada centro formados, pode-se diferenciar três escalas de inserção doutoral: instituições longevas como Iuperj/Uerj-CP e USP revelam tanto maior número de doutores saídos de seus bancos e contratados por outros PPGs, como maior número de cursos de pós-graduação nacionais da área que contam com seus egressos. Em patamar intermediário, Unicamp, Ufrgs e, em menor medida UFPE, PUC-RJ, UnB-RI e UFMG apresentam número mais reduzido e, igualmente, menor extensão nacional na presença de seus titulados no interior de outras instituições. Padrão que predomina entre a maioria das instituições formadoras de doutores na área e de limitada mobilidade geográfica de seus egressos, o que pode ser confirmado pelas elevadas taxas de inserção profissional na mesma região da escolarização, com as exceções representadas por Unicamp e UFMG.

$\mathrm{O}$ ranking acadêmico é relevante para a obtenção de uma vaga docente em um programa de pós-graduação academicamente prestigiado? Programas nota 7 contavam com 20 docentes egressos de outras instituições igualmente nota 7, além de 19 professores formados em centros de Ciência Política no exterior. Isso significa que $81,2 \%$ de seu corpo docente foi recrutado a partir de formação no exterior ou em outros centros nacionais equivalentes. ${ }^{4}$ Entre os programas de CP e RI com notas 6, contingente de 34 (45,9\%) foram formados em outros programas 6 , outros $14(18,9 \%)$ em instituições com nota 7 , enquanto $25(33,8 \%)$ titularam-se no exterior. Apenas $1(1,3 \%)$ obteve seu título em programa com nota inferior (5) ao destino. A presença de docentes com título obtido em instituições com a menor nota para cursos de doutorado (nota 4) aumenta, à medida em que decresce a nota da instituição receptora: 4 docentes em PPGs nota 5, 19 naqueles com nota 4 e 15, nota 3. Em suma, embora hierarquias acadêmicas não pareçam ser definitivas para oportunidades profissionais quando se considera o conjunto das vagas ocupadas por doutores em CP e RI, elas contam na seleção para posições profissionais no interior

\footnotetext{
${ }^{3}$ Evidentemente, egressos de programas de pós-graduação em Ciência Política e Relações Internacionais podem ser absorvidos em programas de outras áreas, como Sociologia, Ciências Sociais, Administração, Economia, Interdisciplinar e outras. Considerar cada uma destas áreas ultrapassaria o escopo deste trabalho e perderia o foco localizado em considerar a correspondência de hierarquia acadêmica no recrutamento docente.

${ }^{4}$ Os nove docentes restantes são originários de programas nacionais nota 6 , não sendo registrado nenhum membro com origem em instituições com notas 5,4 ou 3 .
} 
do sistema de pós-graduação. Vagas ocupadas por cientistas políticos na administração pública ou em departamentos universitários sem pós-graduação parecem mais sensíveis à influência da reduzida mobilidade regional, tornando mais proeminente a influência territorial exercida por cada instituição universitária, independentemente de seu rankeamento nacional. Em contraste, quando se trata de pós-graduação, hierarquias, rankings e antiguidade importam. A hipótese tentativa para esse fenômeno pode ser sugerida pelo fato de que tanto a administração pública quanto o ensino de graduação não contam com um sistema de avaliação institucionalizado constituído pela Capes desde 1976 com efeitos condicionantes sobre cursos de pós-graduação (Marenco, 2015; Durham, 1992). Métricas de produção científica, desempenho na formação de recursos humanos e internacionalização comparativas e competitivas, dentro de um calendário trienal ou quadrienal e com impactos sobre o credenciamento/descredenciamento de cursos e a distribuição de recursos de fomento acadêmico exigem um controle sobre o tamanho e a composição do corpo docente de cada programa, implicando em processos de seleção rigorosos sobre o ingresso e perfil de novos docentes.

\section{Considerações finais}

Este trabalho procurou analisar os efeitos da expansão do sistema de pós-graduação na área de Ciência Política e Relações Internacionais sobre oportunidades de profissionalização dos doutores formados entre 1996 e 2014. Seus achados permitem isolar alguns padrões: (i) taxas de profissionalização elevadas dos doutores em Ciência Política e Relações Internacionais; (ii) uma limitada circulação geográfica nacional; (iii) forte concentração dos empregos pós-doutoramento nas áreas de educação e administração pública: 9 em cada 10 doutores formados na área de Ciência Política e Relações Internacionais tiveram como destino profissional atividades nessas áreas; (iv) recrutamento para programas de pós-graduação com posição mais elevada no rankeamento acadêmico é restritivo a doutores formados em instituições com notas equivalentes ou centros de pesquisa no exterior.

O intervalo temporal considerado nesta análise (1996 a 2014) correspondeu a um período de forte expansão na pós-graduação brasileira paralelo à ampliação de postos na administração pública e no sistema universitário público, especialmente federal a partir de programas como o Reuni, de ampliação no número de universidades federais. Os dados referentes ao último ano de observação (2014) já revelam uma inflexão nessa curva de expansão das instituições públicas. Uma questão futura nessa agenda de pesquisa consiste em responder até que ponto a restrição na abertura de 
concursos públicos na administração pública e sistema universitário federal pode representar mudanças significativas nos padrões observados, sob a forma de direcionamento para o mercado privado (consultorias, ONGs) ou na redução das taxas de empregabilidade e renda.

Em cinco décadas, a Ciência Política brasileira foi capaz de forjar uma "vocação", expressa em instituições, disciplinas e agendas acadêmicas próprias. Os achados deste trabalho indicam que o principal produto desse investimento acadêmico e institucional pode ser identificado na profissionalização dos doutores formados pelos programas e centros de Ciência Política no País.

\section{Referências}

ALMEIDA, Maria Hermínia Tavares de. Ciência Política no Brasil, avanços e desafios. In: MARTINS, Carlos Benedito (org.). Para onde vai a pós-graduação em ciências sociais no Brasil. Bauru: Edusc, 2005. p. 81-103.

AVRITZER, Leonardo; MILANI, Carlos; BRAGA, Maria do Socorro (org.). A ciência política no Brasil: 1960-2015. Rio de Janeiro: FGV, 2016. https://doi. org/10.1590/0103-335220192908

BENZ, Jennifer K. Reflect, then prepare for a career outside the academy. PS: Political Science and Politics, Washington, v. 49, n. 3, p. 504-506, 2016. Disponível em: https:// doi.org/10.1017/s1049096516000834. Acesso em: 22 out. 2019.

BUlCOURF, Pablo; MÁRQUEZ, Enrique Gutiérrez; CARDOZO, Nelson. El desarrollo de la Ciencia Política en Argentina, Brasil y México: construyendo una mirada comparada. Anuario Latinoamericano: Ciencias Politicas y Relaciones Internacionales, [s. l.], v. 1, p. 155-184, 2014. Disponível em: https://doi.org/10.17951/ al.2014.1.0.155. Acesso em: 22 out. 2019.

BULCOURF, Pablo; VAZQUEZ, Juan Cruz. La ciencia política como profesión. Post Data, [s. l.], n. 10, p. 255-304, 2004.

CGEE. Mestres e doutores 2015: estudos da demografia da base técnico-científica brasileira. Brasília: CGEE, 2016.

CLARK, Chelsea. I don't want to be a professor. Now what? PS: Political Science and Politics, Washington, v. 49, n. 3, p. 507-509, 2016. Disponível em: https://doi. org/10.1017/s1049096516000846. Acesso em: 22 out. 2019.

CLAYPOOL, Vicki et al. Determinants of salary dispersion among Political Science Faculty: the differential effects of where you work (institutional characteristics) and what you do (negotiate and publish). PS: Political Science and Politics, Washington, v. 50, n. 1, p. 146-156, 2017. Disponível em: https://doi.org/10.1017/ s104909651600233x. Acesso em: 22 out. 2019. 
DURHAM, Eunice. A institucionalização da avaliação. In: DURHAM, Eunice; SCHWARTZMAN, Simon (org.). Avaliação do ensino superior. São Paulo: Edusp, 1992.

EASTON, David; GRAZIANO, Luigi; GUNNEL, John. The development of political science a comparative survey. London: Routledge, 1991.

FOWLER, James H.; GROFMAN, Bernard; MASUOKA, Natalie. Social networks in political science: hiring and placement of Ph.D.s, 1960-2002. PS: Political Science and Politics, Washington, v. 40, n. 4, p. 729-739, 2007. Disponível em: https://doi. org/10.1017/s104909650707117x. Acesso em: 22 out. 2019.

GOODIN, Robert; KLINGEMANN, Hans-Dieter. Political science: the discipline. In: GOODIN, Robert; KLINGEMANN, Hans-Dieter (org.). A new handbook of political science. Oxford: Oxford University Press, 1996. p. 3-49. Disponível em: https://doi. org/10.1017/s0048840200028999. Acesso em: 22 out. 2019.

GROFMAN, Bernard; FELD, Scott; MASUOKA, Natalie. Direct and indirect influence among political science departments. UC Irvine: Center for the Study of Democracy, 2005. Disponível em: https://escholarship.org/uc/item/5t1223d4. Acesso em: 22 out. 2019.

GUIMARÃES, Reinaldo. A diáspora: um estudo exploratório sobre o deslocamento geográfico de pesquisadores brasileiros na década de 90. Dados, Rio de Janeiro, v. 45, n. 4, p. 705-750, 2002. Disponível em: https://doi.org/10.1590/S001152582002000400006. Acesso em: 22 out. 2019.

GUNDERSEN, Adolf. Neither star, nor gypsy: how I found happiness outside academy, PS: Political Science and Politics, Washington, v. 49, n. 3, p. 513-515, 2016. Disponível em: https://doi.org/10.1017/S104909651600086X. Acesso em: 22 out. 2019.

GUNNEL, John G. Founding of the American Political Science Association: discipline, profession, political theory, and politics. The American Political Science Review, Baltimore, v. 100, n. 4, p.479-483, 2006. Disponível em: https://doi.org/ 10.1017/S0003055406062320. Acesso em: 23 out. 2019.

IBGE. Classificação nacional de atividades econômicas, versão 2.0. Brasília: IBGE, 2007.

KLARNER, Carl. Beyond the ivory tower: political science careers outside academia. PS: Political Science and Politics, Washington, v.49, n.3, p.501-504, 2016. Disponível em: https://doi.org/10.1017/S1049096516000822. Acesso em: 22 out. 2019.

LEITE, Fernando; CODATO, Adriano; PERISSINOTTO, Renato. Midiendo el capital académico de la Ciencia Política y la Sociología Política producida en Brasil. Anuario Latinoamericano: Ciencias Políticas y Relaciones Internacionales, [s.l.], v. 5, p.61-79, 2018. Disponível em: https://doi.org/10.17951/al.2017.5.61. Acesso em: 22 out. 2019. 
LEWIS, Gregory. Do political science majors succeed in the labor market? PS: Political Science and Politics, Washington, v. 50, n. 2, p.467-472, 2017. Disponível em: https://doi.org/10.1017/S1049096516003012. Acesso em: 22 out. 2019.

MADEIRA, Rafael Machado; MARENCO, André. Os desafios da internacionalização: mapeando dinâmicas e rotas da circulação internacional. Revista Brasileira de Ciência Política, Brasília, v. 19, p.47-74, 2016. Disponível em: https://doi.org/10.1590/0103335220161903. Acesso em: 22 out. 2019.

MARENCO, André. The three Achilles' heels of Brazilian political science. Brazilian Political Science Review, São Paulo, v. 8, n. 3, p. 3-38, 2014. Disponível em: https:// doi.org/10.1590/1981-38212014000100019. Acesso em: 22 out. 2019.

MARENCO, André. When institutions matter: Capes and political science in Brazil, Revista de Ciência Política, Santiago, v. 35, n. 1, p.33-46, 2015. Disponível em: https://doi.org/10.4067/S0718-090X2015000100003. Acesso em: 22 out. 2019.

MASUOKA, Natalie; GROFMAN, Bernard; FELD, Scott L. The production and placement of Political Science Ph.D.s, 1902-2000. PS: Political Science and Politics, Washington, v. 40, n. 2, p.361-366, 2007. Disponível em: https://doi.org/10.1017/ S1049096507070576. Acesso em: 22 out. 2019.

MICELI, Sérgio. História das Ciências Sociais no Brasil. São Paulo: Sumaré, 1995.

OPRISKO, Robert; DOBBS, Kirstie; DIGRAZIA, Joseph. Honor, prestige, and the academy: a portrait of political science tenured and tenure: track faculty in Ph.D. granting institutions (2012-2013). In: Annual meeting of the American Political Science Association, 2013, Chicago. Proceedings [...]. Chicago: [s. n.], 2013.

RANNEY, Austin. Political Science: the state of the profession: a review article. Political Science Quarterly, New York, v. 80, n. 2, p. 277-287, 1965. Disponível em: https://doi.org/10.2307/2147743. Acesso em: 22 out. 2019.

SOMIT, Albert; TANENHAUS, Joseph. American political science: a profile of the discipline. New York: Atherton, 1964.

SOMIT, Albert; TANENHAUS, Joseph. The development of American political science: from Burgess to behavioralism. New York: Allyn and Bacon, 1967. https:// doi.org/10.1177/106591296902200135

SOMIT, Albert; TANENHAUS, Joseph. Trends in American political science: some analytical notes. The American Political Science Review, Baltimore, v. 57, n. 4, p.933-938, 1963. Disponível em: https://doi.org/10.2307/1952610 . Acesso em: 22 out. 2019. 
VELHO, Lea. Formação de doutores no país e no exterior: estratégias alternativas ou complementares? Dados, Rio de Janeiro, v. 44, n. 3, p. 607-631, 2001. Disponível em: https://doi.org/10.1590/S0011-52582001000300005. Acesso em: 22 out. 2019.

Recebido em: 7/1/2019.

Aprovado em: 27/5/2019.

Publicado em: 15/12/2019.

Endereço postal:

Av. Bento Gonçalves, 9500

Prédio 43322 (IFCH), sala 225

91509-900, Porto Alegre, RS, Brasil

ANDRÉ MARENCO <amarencoufrgs@gmail.com>

Doutor em Ciência Política pela Universidade Federal do Rio Grande do Sul (Ufrgs, Porto Alegre, RS, Brasil). Professor titular do departamento de Ciência Política e do Programa de Pós-Graduação em Políticas Públicas da Universidade Federal do Rio Grande do Sul (Ufrgs, Porto Alegre, RS, Brasil).

Orcid: http://orcid.org/0000-0002-0848-9352 